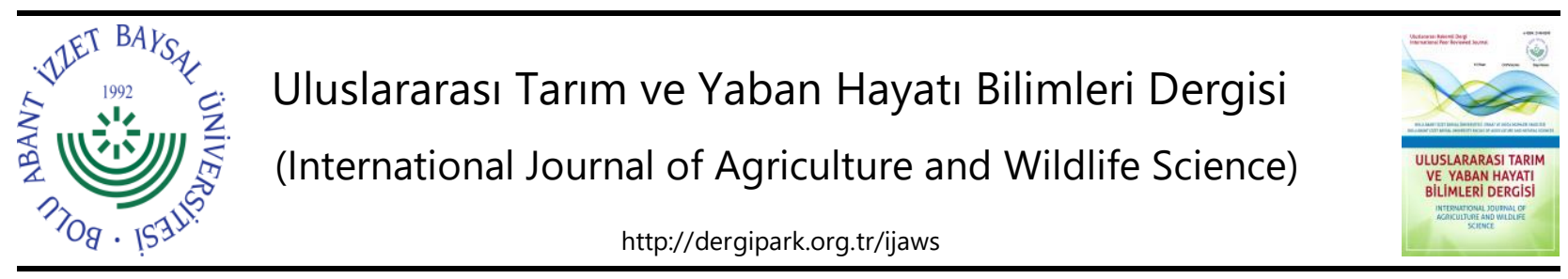

Araştırma Makalesi

\title{
Ultraviyole-C ve Ultrason Uygulamalarının Domates ve Hıyarda Fide Gelişimi Üzerine Etkilerinin Belirlenmesi
}

\author{
Beyhan Kibar \\ Bolu Abant İzzet Baysal Üniversitesi, Ziraat Fakültesi, Bahçe Bitkileri Bölümü, Bolu \\ Geliş tarihi (Received): 21.10.2020Ｋabul tarihi (Accepted): 24.11.2020
}

\begin{abstract}
Anahtar kelimeler: Solanum lycopersicum L., Cucumis sativus L., ultraviyole-C, ultrason, fide
\end{abstract}

*Sorumlu yazar

beyhan.kibar@ibu.edu.tr

\begin{abstract}
Özet. Günümüzde bitki büyümesini teşvik etmek amacıyla çevre dostu alternatif fiziksel yöntemlere yönelik yoğun araştırmalar yapılmaktadır. Bu çalışma, fiziksel yöntemler arasında yer alan ultraviyole-C ve ultrason uygulamalarının dünyada ve ülkemizde en fazla yetiştiriciliği yapılan yazlık sebze türlerinden domates ve hıyarda fide gelişimi üzerine etkilerini belirlemek amacıyla yapılmıştır. Bitkisel materyal olarak Falcon ve $\mathrm{H}-2274$ domates çeşitleri ile Prima ve Beith Alpha hıyar çeşitlerinin kullanıldığı çalışmada 1) Kontrol, 2) Ultraviyole-C (UV-C), 3) Ultrason (US) ve 4) UV-C+US uygulamaları ele alınmıştır. Çalışmada fide boyu, gövde çapı, kök uzunluğu, fide yaş ve kuru ağırlı̆ı̆, yaprak sayısı ve klorofil miktarı belirlenmiştir. Araştırma sonucunda UV-C, US ve UV-C+US uygulamalarının kontrole göre fide büyüme parametreleri üzerine olumlu etkilerinin olduğu belirlenmiştir. UV-C+US uygulamasının araştırmada ele alınan 4 çeşitte de fide gelişimi üzerine daha etkili olduğu ve kontrol uygulaması ile karşılaştııılığında, çeşitlere bağlı olarak fide boyu, fide yaş ağırlığı ve fide kuru ağırlığını sırasıyla \%16.99-45.11, \%24.82-39.88 ve \%37.93-52.63 oranında artırdığı belirlenmiştir. Sonuç olarak, UV-C ve US uygulamaları ile her ikisinin kombinasyonunun domates ve hıyarda fide gelişimini artırmada alternatif bir uygulama yöntemi olarak kullanılabileceği tespit edilmiştir.
\end{abstract}

\section{Determination of the Effects of Ultraviolet-C and Ultrasound Applications on Seedling Growth in Tomato and Cucumber}

\author{
Keywords: \\ Solanum lycopersicum L., \\ Cucumis sativus L., \\ ultraviolet-C, ultrasound, \\ seedling
}

\begin{abstract}
Nowadays, intensive researches are carried out on environment friendly alternative physical methods to promote plant growth. This study was conducted to determine the effects of ultraviolet- $C$ and ultrasound applications, which are among physical methods, on seedling growth in tomato and cucumber, which are the most cultivated summer vegetables in the world and in our country. In the study where Falcon and H-2274 tomato varieties and Prima and Beith Alpha cucumber varieties were used as herbal material, 1) Control, 2) Ultraviolet-C (UV-C), 3) Ultrasound (US) and 4) UV-C+US applications were evaluated. In the study, seedling height, stem diameter, root length, seedling fresh and dry weight, number of leaves and chlorophyll content were determined. As a result of the research, it was determined that UV-C, US and UV-C+US applications had positive effects on the seedling growth parameters compared to the control. It was detected that UV-C+US application was more effective on seedling growth in all 4 varieties discussed in the research. When compared to the control application, UV-C+US application increased seedling height, seedling fresh weight and seedling dry weight by $16.99-45.11 \%, 24.82-39.88 \%$ and $37.93-$ $52.63 \%$, respectively, depending on the varieties. As a result, it was determined that UV-C, US and UV-C+US applications can be used as an alternative application method to increase seedling growth in tomato and cucumber.
\end{abstract}




\section{GíRiş}

Domates (Solanum lycopersicum L.), patlıcangiller (Solanaceae) familyasında yer alan bir sıcak iklim sebzesidir. Domatesin anavatanı Orta ve Güney Amerika'dır. Domates, Akdeniz ülkeleri başta olmak üzere dünya genelinde ekonomik olarak büyük öneme sahip bir sebzedir (Amini ve Ehsanpour, 2005). Meyveleri tüketilen sebzeler arasında yer alan domates içerdiği vitaminler, likopen ve mineral maddeler bakımından insanların vazgeçilmez temel gıdalarından birisidir. Besleyici özelliği ve lezzetinden dolayı dünyada ve Türkiye'de en çok üretilen, tüketilen ve ticareti yapılan sebzelerden biri olan domatesin pek çok kullanım alanı bulunmaktadır. Domates sofralık tüketiminin yanında, salça, ketçap, konserve, turşu, dondurularak, kurutularak, domates suyu ve domates püresi yapılarak gıda sanayinde kullanılmaktadır (Vural ve ark., 2000). Dünya domates üretiminde Çin, Hindistan ve Amerika ilk üç sırayı paylaşmaktadır. Türkiye, domates üretimi bakımından dünyada 4. sırada yer almaktadır (FAOSTAT, 2018). Ülkemizde 2019 yılı verilerine göre 542.442 da alanda 4.005 .935 ton salçalık ve 1.191 .772 da alanda 8.836.055 ton sofralık olmak üzere toplam 12.841 .990 ton domates üretimi yapılmıştır (TÜiK, 2020). Ülkemiz ekonomisinde çok önemli bir yeri olan domates, yetiştiriciliği yapılan bölgelerde çiftçimizin önemli gelir kaynaklarından birisini oluşturmaktadır. Domates, açıkta ve örtü altında üretilmektedir.

Hıyar (Cucumis sativus L.), kabakgiller (Cucurbitaceae) familyasına ait olup, dünyada ve ülkemizde en fazla yetiştiriciliği yapılan yazlık sebze türlerinden biridir. Hıyarın anavatanı Hindistan'dır. Hıyar meyveleri esas olarak taze salata ürünü ve turşu şeklinde tüketilmektedir (Sharma ve Hore, 1996). Ayrıca kozmetik ürünlerinde krem ham maddesi olarak kullanılmaktadır (Dhiman ve Prakash, 2005). Hıyar, su oranı oldukça yüksek ve kalorisi düşük olduğu için iyi bir diyet yiyeceğidir. Türkiye hıyar üretimi bakımından dünyada Çin'den sonra 2. sırada yer almaktadır (FAOSTAT, 2018). Ülkemizde 2019 yılı verilerine göre 289.287 da alanda 1.748 .157 ton sofralık ve 70.895 da alanda 168.488 ton turşuluk hıyar üretimi olmak üzere toplam hıyar üretimi 1.916 .645 ton olarak tespit edilmiştir (TÜiK, 2020). Hıyar ülkemizde hem açıkta hem de örtü altında yaygın olarak yetiştirilen ve ekonomik açıdan önemli bir sebze türüdür.

Sebze üretiminde başarıyı etkileyen en önemli faktörlerden birisi, iyi bir tohum ve bundan elde edilecek kaliteli fidedir. Kaliteli fide ile üretime başlamak hem verimi artırmak hem de kaliteli ürün elde etmek için büyük önem taşımaktadır. Kaliteli bir fide; hastalık ve zararlılardan ari, pişkin ve kuru maddece zengin, 4-5 gerçek yapraklı, taç ve kök gelişimi dengeli, kalın ve kuvvetli bir gövdeye, koyu yeşil yapraklara, canlı ve kuvvetli bir kök yapısına sahip olmalıdır (Vural ve ark., 2000). Birçok sebze türünde, özellikle sera yetiştiriciliğinde zamandan, yerden ve enerjiden tasarruf gibi faktörlerden dolayı, tarlada doğrudan tohum ekimi yerine fide ile yetiştirme yöntemi kullanılmaktadır. Ülkemizde sebze üretiminin artışına paralel olarak son yıllarda sebze yetiştiriciliğinde hazır fide üretimi ve kullanılması da hızla yaygınlaşmaktadır. Türkiye'de toplam sebze fide üretiminin 2017 yılında 2.9 milyar adet olduğu bildirilmektedir. Fide üretimi yapılan sebze türlerinden domates ilk sırayı alırken; bunu marul, biber, lahanagiller, hıyar ve karpuz izlemektedir (Tüzel ve ark., 2020).

Günümüzde tarımsal üretimde toprak, çevre ve insan sağlığının korunması amacıyla alternatif fiziksel yöntemlere yönelik yoğun araştırmalar yapılmaktadır (Vasilevski, 2003). Son zamanlarda bitki büyümesini teşvik etmek için fiziksel yöntemlerinin kullanımına olan ilgi artmıştır. Ekim öncesi fiziksel uygulamalar çimlenme, çıkış, fide ve bitki gelişimi üzerinde faydalı etkiler sağlayabilmektedir (Aladjadjiyan, 2012; Dhanya Thomas ve Puthur, 2017). Fiziksel yöntemler arasında; elektromanyetik dalgalar, manyetik alan, ultraviyole ışınlar, ultrason, iyonlaştırıcı radyasyon (gama ışıları ve $\mathrm{X}$-ışınları), lazer, led ve mikrodalga teknikleri yer almaktadır (Dhanya Thomas ve Puthur, 2017; Rifna ve ark., 2019).

Ultraviyole (UV) ışık, elektromanyetik spektrumun iyonlaşmayan kısmında bulunmakta ve toplam güneş ışığının \%8-9'luk kısmını oluşturmaktadır (Frederick, 1993). UV ışığı, X ışınları ile görünür bölge ışınları arasında yer almaktadır (Shetta ve Areaf, 2009). UV ışınları farklı dalga boylarına göre UV-A (320-400 nm), UV-B (280-320 nm) ve UV-C (200-280 nm) olmak üzere 3'e ayrılmaktadır (Katerova ve Todorova, 2009; Shetta ve Areaf, 2009). UV-A dünya üzerine gelen güneş ışığının \%6-7'sini oluşturmakta ve UV ışıkları içerisinde en az zararlı etki yaratan ışık olarak değerlendirilmektedir (Hollosy, 2002; Koutchma, 2009). UV-B, toplam spektrumun \% $1.5^{\prime}$ ini oluşturmasına rağmen canlı organizmalarda farklı zararlı etkilere neden olabilmektedir. UV-C, doğal güneş ışı̆̆ında bulunmayıp, canlılar için oldukça zararlı yapıdadır. UV-C ürünlerin hasat sonrasında yüzey dezenfeksiyonu için kullanılmaktadır. Farklı dalga boylarındaki UV ışınları, bitki büyüme ve gelişimine farklı şekillerde etki yapmaktadır. UV uygulaması bitkilerde morfolojik, fizyolojik ve biyokimyasal değişimlere neden olabilmektedir (Dhanya Thomas ve Puthur, 2017). Düşük dozlardaki UV uygulamasının tohum çimlenmesi, bitki gelişimi ve verimini artırdığı, karotenoid, antosiyanin, klorofil gibi pigment maddeleri ve fotosentezi teşvik ettiği, antioksidan enzim aktivitesini artırdığı, bitkinin biyotik ve abiyotik stres koşullarına tolerans kazanmasında etkili olduğu bildirilmektedir (Siddiqui ve ark., 2011; Dhanya Thomas ve Puthur, 2017). Tohum veya fidelere düşük seviyelerde UV uygulanması ekolojik olarak güvenli bir yöntemdir ve çevre dostu bir alternatiftir (Dhanya Thomas ve Puthur, 2017). 
Ultrason, insanın işitme sistemi tarafından algılanamayan ve $20-100 \mathrm{kHz}$ frekansa sahip mekanik dalgalardır (Awad ve ark., 2012). Son yıllarda, ultrasonik dalgalar tohum dormansisini kırmak, çimlenme özelliklerini iyileştirmek ve ürün üretimini artırmak için etkili bir teknik olarak büyük ölçüde uygulanmaktadır (Ramteke ve ark., 2015). Ultrason genellikle güvenli, uygulanması kolay, ucuz ve çevre dostu bir yöntem olması nedeniyle, diğer fiziksel tekniklere göre büyük bir avantaj sağlamaktadır (Awad ve ark., 2012). Çok sayıda araştırııı yaptıkları çalışmalarda ultrason uygulamasının tohum çimlenmesi, bitki büyümesi, gelişmesi ve verimi üzerinde teşvik edici etkilerinin olduğunu bildirmişlerdir (Yang ve ark., 2004; Kim ve ark., 2006; Goussous ve ark., 2010; Wang ve ark., 2012). Ultrasonun tohumlar üzerindeki etki mekanizmaları konusunda, suda ultrasonik dalgaların mikro kabarcıklar oluşturarak kavitasyona neden olduğu, kavitasyonun tohumun hücre duvarına mekanik bir basınç uyguladığı, bu basıncın tohumun gözenekliliğini artırarak oksijen ve su geçirgenliğini artırdığı, bunun sonucunda hidrasyonun ve enzimatik aktivitelerin artması ile tohumun çimlenme yüzdesi ve hızının arttığı bildirilmektedir (Yaldagard ve ark., 2008).

Dünyada farkı sebze türlerinde yapılan çalışmalar ultrason ve UV uygulamalarının tohum çimlenmesi, fide büyümesi ve bitki gelişimi üzerinde önemli etkilerinin olduğunu ortaya koymuştur (Kacharava ve ark., 2009; Goussous ve ark., 2010; Stratu ve ark., 2010; Fotouh ve ark., 2014; Ouhibi ve ark., 2014; Ramteke ve ark., 2015; Mariz-Ponte ve ark., 2018; Sarı, 2019). Bununla birlikte, ülkemizde bu konuda sınırlı sayıda çalışma bulunmaktadır. UV ve ultrason uygulamalarının ülkemizdeki üretim potansiyeli yüksek olan domates ve hıyarda fide gelişimini nasıl etkilediğinin belirlenmesi oldukça önem taşımaktadır. Bu çalışma, hem dünyada hem de ülkemizde yüksek oranda üretilen ve tüketilen sebze türleri arasında yer alan domates ve hıyarda UV-C ve ultrason uygulamalarının fide gelişimi üzerine etkilerini araştırmak amacıyla yürütülmüştür.

\section{MATERYAL VE METOT}

Araştırma, Ekim 2019-Aralık 2019 tarihleri arasında, Bolu Abant İzzet Baysal Üniversitesi Ziraat Fakültesi Bahçe Bitkileri Bölümü'ne ait laboratuvar ve iklim odasında yürütülmüştür. Çalışmada bitkisel materyal olarak Falcon ve $\mathrm{H}-2274$ domates çeşitleri ile Prima ve Beith Alpha hıyar çeşitlerinin tohumları kullanılmıştır.

Çalışmada 1) Kontrol, 2) Ultraviyole-C (UV-C), 3) Ultrason (US) ve 4) UV-C+US uygulamaları ele alınmıştır. Domates ve hıyar tohumlarına ekim öncesi çalışmada ele alınan uygulamalar yapılmıştır. Her bir çeşitten 150 tohuma uygulama yapılmıştır. Uygulamalar öncesi tohumlar dezenfeksiyon için \%1'lik sodyum hipoklorit ( $\mathrm{NaClO}$ ) içinde $5 \mathrm{dk}$ bekletilmiş ve sonrasında 30 saniye musluk suyunda yıkanmıştır. Kontrol uygulamasında tohumlar dezenfeksiyon sonrası herhangi bir işleme tabi tutulmadan ekilmiş̧ir. Ultraviyole-C uygulamasında $90 \mathrm{~cm}$ uzunluğunda, $30 \mathrm{~W}$ çıkışlı, $254 \mathrm{~nm}$ dalga boyunda ultraviyole ışık veren lamba (Osram HNS 30W) kullanılmıştır. Uygulama kabini içerisinde tohumlara $50 \mathrm{~cm}$ mesafeden 30 dakika boyunca UV-C ışık uygulaması yapılmıştır (Kacharava ve ark., 2009). Ultrason uygulamasında 35 kHz, 120-480 W değerlerine sahip $4 \mathrm{~L}$ hacminde ultrasonik banyo (Bandelin Sonorex Super RK $102 \mathrm{H}$ Model) kullanılmıştır. Ultrason uygulamasında tohumlar 10 dakika boyunca $35 \mathrm{kHz}$ frekansında ve $20^{\circ} \mathrm{C}$ sıcaklıktaki saf su içerisinde bekletilmiştir (Babu ve Swamy, 2012). UV-C+US uygulamasında ise tohumlar 10 dakika boyunca ultrason cihazında bekletilmiş ve daha sonra 30 dakika boyunca UV-C ışık uygulaması yapılmıştır.

Fide yetiştiriciliği, $23 \pm 1{ }^{\circ} \mathrm{C}$ ortam sıcaklığı, \%55-60 nem ve 16 saat ışık / 8 saat karanlık periyoda sahip iklim odasında yapılmıştır. Deneme tesadüf parselleri deneme desenine göre 3 tekerrürlü olarak kurulmuştur. Her tekerrürde 10 fide olacak şekilde her iki türden toplam (4 çeşit x 4 uygulama x 3 tekrar x 10) 480 fide yetiştirilmiştir. Domates ve hıyar tohumları 3:1 oranında ( $\mathrm{v} / \mathrm{v}$ ) torf:perlit karışımı ile doldurulmuş 45'lik viyollere 1-1.5 cm derinliğe her gözde 1 tohum olacak şekilde ekilmiştir. Tohum ekimi sonrası viyollere kapak olarak vermikülit ilavesi ve ardından sulama yapılmıştır. Illk çıkışlar tohum ekiminden sonraki 2-5 gün içerisinde gözlemlenmiştir. Yetiştirme periyodu boyunca nem durumu kontrol edilerek gerekli görüldügüunde sulama yapılmıştır. Fidelere herhangi bir kimyasal gübre veya ilaç uygulanmamıştır. Tohum ekiminden 30 gün sonra deneme sonlandırılmış ve uygulamaların etkilerini belirlemek amacıyla fideler topraktan kökleri ile birlikte sökülerek fide büyüme parametreleri belirlenmiştir.

Çalışmada fide boyu (cm), gövde çapı (mm), kök uzunluğu (cm), fide yaş ağırlığı (g), fide kuru ağırlığı (g), yaprak sayısı (adet bitki ${ }^{-1}$ ) ve klorofil değeri (spad) tespit edilmiştir. Çalışmada fide boyu ve kök uzunluğu cetvel yardımıyla ölçülerek; fide yaş ağırlığı hassas terazide tartılarak; fide kuru ağırlığı etüvde $65^{\circ} \mathrm{C}^{\prime}$ de sabit ağırlığa ulaşana kadar kurutulduktan sonra hassas terazide tartılarak; gövde çapı dijital kumpasla ölçülerek; yaprak sayısı fidelerde oluşan gerçek yapraklar sayılarak; klorofil miktarı tam olarak gelişmiş yapraklarda klorofil ölçer (Apogee Chlorophyll Concentration Meter, MC-100) ile belirlenmiştir. 
Araştırma sonucunda elde edilen veriler JMP 13.2 istatistik programı kullanılarak varyans analizine tabi tutulmuştur. İncelenen özellikler bakımından istatistiki olarak önemli bulunan ortalamalar arasındaki farklılıklar Tukey HSD (Tukey's Honestly Significant Difference Test) çoklu karşılaştırma testi ile belirlenmiştir.

\section{BULGULAR VE TARTIŞMA}

Falcon domates çeşidinde farklı uygulamaların fide büyüme parametreleri üzerine etkileri Şekil 1'de verilmiştir. Fide boyu, gövde çapı, kök uzunluğu, fide yaş ağılığı ve yaprak sayısı bakımından uygulamalar arasındaki farklııklar $\mathrm{P}<0.01$ düzeyinde önemli; fide kuru ağırlığı bakımından ise uygulamalar arasındaki farklılıklar $\mathrm{P}<0.05$ düzeyinde önemli bulunmuştur. Buna karşılık, klorofil miktarı yönünden uygulamalar arasındaki farklılıkların önemsiz ( $P>0.05$ ) olduğu tespit edilmiştir. En yüksek fide boyu US ve UV-C+US uygulamalarında (sırasıyla 8.22 ve $8.20 \mathrm{~cm}$ ) belirlenmiştir. En düşük fide boyu ise kontrol uygulamasında $(6.47 \mathrm{~cm})$ saptanmıştır. US ve UV-C+US uygulamaları kontrole göre fide boyunu sırasıyla \%27.05 ve \%26.74 oranında artırmıştır. En yüksek gövde çapı $2.47 \mathrm{~mm}$ ile US uygulamasında belirlenmiş olup, onu istatistiksel olarak aralarında fark olmayan UV-C+US uygulaması $(2.41 \mathrm{~mm}$ ) yakından takip etmiştir. En düşük gövde çapı $1.81 \mathrm{~mm}$ ile kontrolde saptanmıştır. Gövde çapı yönünden de ele alınan uygulamalarının kontrole göre önemli artışlar sağladığı tespit edilmiştir. Domates fidelerinde kök uzunluğu 7.44-8.69 cm arasında değişmiş olup, en yüksek UV-C+US uygulamasında, en düşük ise kontrol uygulamasında gözlenmiştir. Fide boyu ve gövde çapında olduğu gibi fide yaş ağırlığı yönünden de en yüksek değerler istatistiksel olarak aynı grupta yer alan US ve UV-C+US uygulamalarında (sırasıyla 1.75 ve $1.71 \mathrm{~g}$ ) belirlenmiştir. En düşük fide yaş ağırlığı ise kontrolde $(1.37 \mathrm{~g})$ tespit edilmiştir. Kontrol uygulaması ile karşılaştırıldığında, US ve UV-C+US uygulamaları fide yaş ağırlığında sırasıyla \%27.74 ve \%24.82 oranında artış sağlamıştır. Fide kuru ağırlığı bakımından çalışmada ele alınan uygulamalar incelendiğinde, UV-C+US ve US uygulamaları (sırasıyla 0.33 ve $0.32 \mathrm{~g}$ ) yine ilk sırada yer almış olup, onları istatistiksel olarak aynı grupta yer alan UV-C uygulaması $(0.25 \mathrm{~g})$ yakından izlemiştir. En düşük fide kuru ağırlığı ise $(0.22 \mathrm{~g})$ kontrolde gözlenmiştir. Domates fidelerinde yaprak sayısı bakımından en yüksek değerler istatistiksel olarak aynı grupta yer alan US ve UV-C+US uygulamalarında (sırasıyla 3.05 ve 3.00) belirlenmiştir. En düşük yaprak sayısı ise istatistiksel olarak aralarında fark olmayan kontrol ve UV-C uygulamalarında (2.75) tespit edilmiştir. İstatistiksel olarak farklılık göstermemekle beraber klorofil değeri bakımından UV-C, US ve UV-C+US uygulamalarından kontrole göre daha yüksek değerler elde edilmiştir. Falcon domates çeşidinde UV-C, US ve her ikisinin kombinasyonunun incelenen fide büyüme parametreleri üzerinde olumlu etkilerinin olduğu tespit edilmiştir (Şekil 1).

Şekil 2'de görüldüğü gibi H-2274 domates çeşidinde, fide boyu, gövde çapı, fide yaş ağırlığı ve fide kuru ağırlığı bakımından uygulamalar arasındaki farklııklar $\mathrm{P}<0.01$ düzeyinde önemli; klorofil değerleri bakımından ise uygulamalar arasındaki farklılıklar $\mathrm{P}<0.05$ düzeyinde önemli bulunmuştur. Diğer taraftan, kök uzunluğu ve yaprak sayısına uygulamaların etkisi önemsiz $(P>0.05)$ bulunmuştur. Çalışmada ele alınan uygulamalara bağlı olarak fide boyu ve fide kuru ağırlığı sırasıyla 6.58-8.31 cm ve 0.21-0.33 g arasında değişmiş olup, en yüksek değerler istatistiksel olarak aynı grupta yer alan UV-C, UV-C+US ve US uygulamalarında, en düşük değerler ise kontrolde belirlenmiştir. Nitekim, uygulamalara bağlı olarak kontrole göre fide boyunun \%25.38-26.29 oranında ve fide kuru ağırlığının \%19.05-57.14 oranında arttığı saptanmıştır. H-2274 domates çeşidine ait fidelerde gövde çapı ve fide yaş ağırlığı bakımından en yüksek değerler istatistiksel olarak aralarında fark olmayan UV-C (sırasıyla $2.43 \mathrm{~mm}$ ve $1.85 \mathrm{~g}$ ) ve UV-C+US (sırasıyla $2.38 \mathrm{~mm}$ ve $1.84 \mathrm{~g}$ ) uygulamalarında gözlenmiş, en düşük değerler ise kontrolde (sırasıyla $1.86 \mathrm{~mm}$ ve $0.21 \mathrm{~g}$ ) tespit edilmiştir. Çalışmada UV-C ve UV-C+US uygulamaları ile kontrole göre gövde çapında (sırasıyla \%30.65 ve \%27.96 oranında) ve fide yaş ağırlığında (sırasıyla \%31.21 ve \%30.50 oranında) önemli düzeyde artışlar sağlanmıştır. Klorofil değeri bakımından UV-C+US uygulaması (36.51 spad) ilk sırada yer almış, UV-C uygulaması onu yakından takip etmiştir. US ve kontrol uygulamaları ise en düşük klorofil içeriğine sahip bulunmuştur. $\mathrm{H}-2274$ domates çeşidinde UV-C, US ve her ikisinin kombinasyonunun kontrole göre kök uzunluğu ve yaprak sayısı hariç incelenen fide büyüme parametrelerini önemli oranda artırdığı belirlenmiştir (Şekil 2).

Prima hıyar çeşidinde farklı uygulamaların fide büyüme parametreleri üzerine etkileri Şekil 3'te verilmiştir. Incelenen tüm özellikler bakımından çalışmada ele alınan uygulamalar arasındaki farklılık istatistiksel olarak önemli $(\mathrm{P}<0.01)$ bulunmuştur. Fide boyu, fide yaş ağılığı, yaprak sayısı ve klorofil içeriği bakımından UV-C+US uygulaması ilk sırada yer alırken, kontrol uygulaması son sırada bulunmuştur. Kontrol uygulaması ile karşılaştıııldığında, UV-C+US uygulaması fide boyunu \%45.11 oranında, fide yaş ağırlığını \%39.88 oranında, yaprak sayısını \%68.09 oranında ve klorofil içeriğini \%19.84 oranında artırmıştır. En yüksek gövde çapı istatistiksel olarak aynı grupta yer alan US ve UV-C+US uygulamalarında (sırasıyla 3.12 ve $3.05 \mathrm{~mm}$ ) belirlenirken, en düşük gövde çapı kontrol ve UV-C uygulamalarında saptanmıştır. Kök uzunluğu 6.82-8.80 cm arasında değişmiş olup, en yüksek US uygulamasında, en düşük ise kontrolde gözlenmiştir. Fide kuru ağırlığı bakımından çalışmada ele alınan uygulamalar incelendiğinde, en yüksek değerler istatistiksel olarak aralarında fark olmayan UV-C+US, US 
ve UV-C uygulamalarında (sırasıyla $0.29,0.28$ ve $0.24 \mathrm{~g}$ ) gözlenmiş, en düşük değer ise $0.19 \mathrm{~g}$ ile kontrolde tespit edilmiştir. Uygulamalara bağlı olarak fide kuru ağılığında kontrole göre \%26.32-52.63 oranında artış meydana gelmiştir. Prima hıyar çeşidinde gövde çapı hariç incelenen tüm özellikler bakımından UV-C, US ve UV-C+US uygulamalarından kontrole göre önemli derecede daha yüksek değerler elde edilmiştir (Şekil 3).
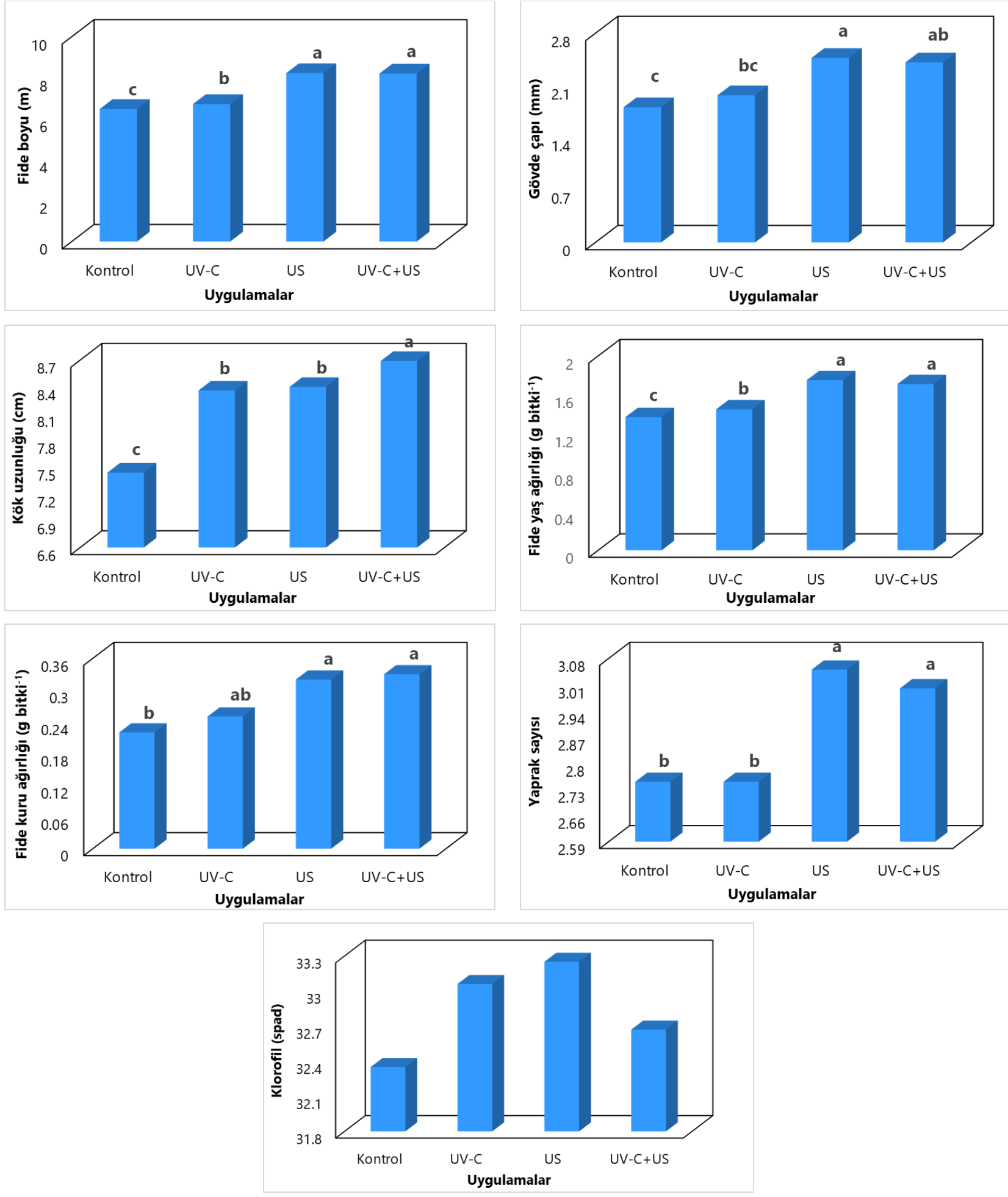

Şekil 1. Falcon domates çeşidinde farklı uygulamaların fide büyüme parametreleri üzerine etkileri. Figure 1. Effects of different applications on seedling growth parameters in Falcon tomato variety. 

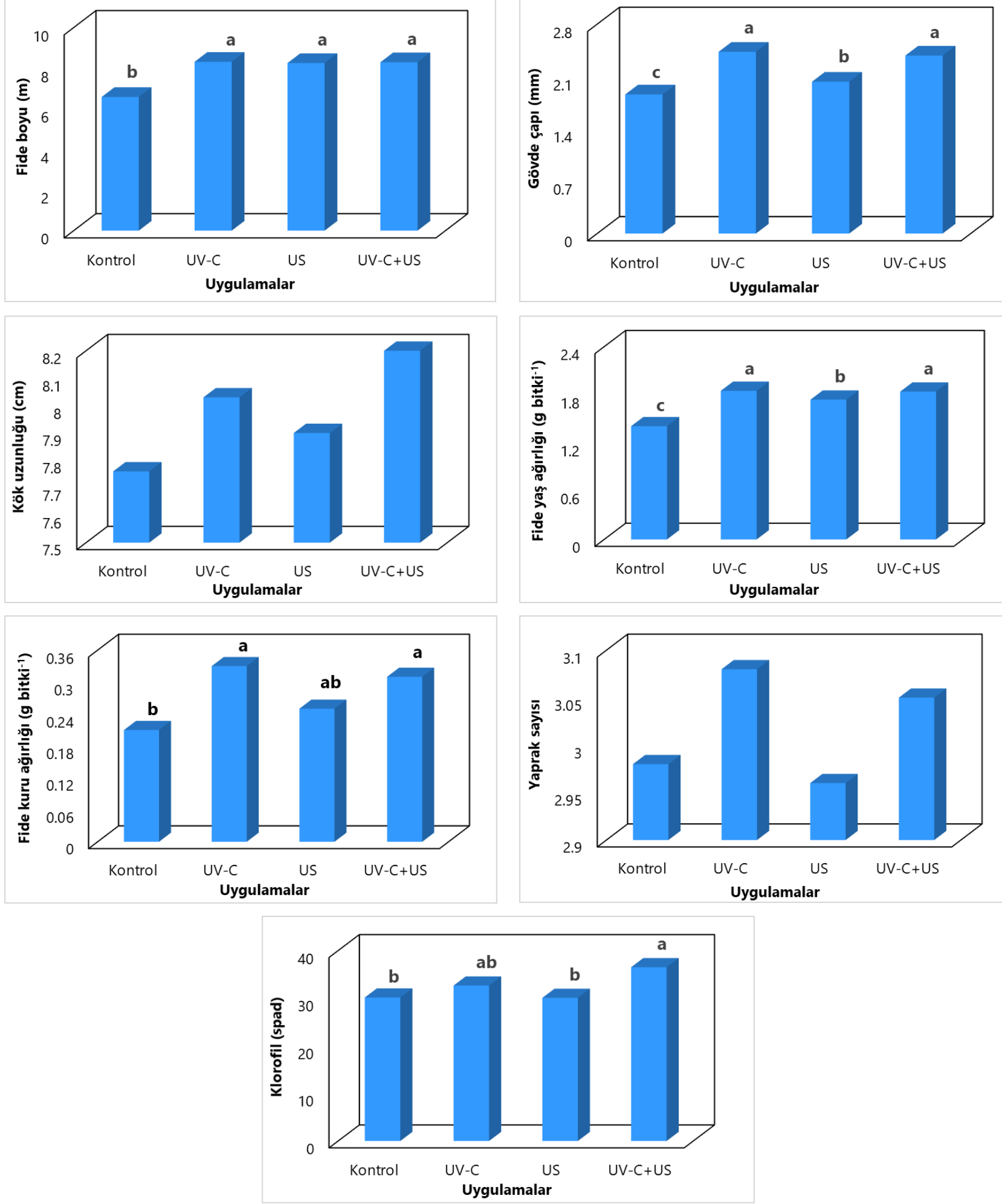

Şekil 2. H-2274 domates çeşidinde farklı uygulamaların fide büyüme parametreleri üzerine etkileri. Figure 2. Effects of different applications on seedling growth parameters in H-2274 tomato variety.

Şekil 4'te görüldüğü gibi Beith Alpha hıyar çeşidinde fide boyu, gövde çapı, fide yaş ağılığı, fide kuru ağırlığı ve klorofil içeriği bakımından uygulamalar arasındaki farklılıklar istatistiksel olarak önemli $(P<0.01)$ iken, kök uzunluğu ve yaprak sayısına uygulamaların etkisi önemsiz $(P>0.05)$ bulunmuştur. Çalışmada ele alınan uygulamalar incelendiğinde, fide boyu, gövde çapı, fide yaş ağırlığı ve fide kuru ağırlığı bakımından en yüksek değerler UV-C+US uygulamasında (sırasıyla $8.47 \mathrm{~cm}, 3.55 \mathrm{~mm}, 3.15 \mathrm{~g}$ ve $0.40 \mathrm{~g}$ ) belirlenirken, en düşük değerler istatistiksel olarak aynı grupta yer alan kontrol ve US uygulamalarında gözlenmiştir. Kontrol uygulaması ile karşılaştırıldığında, UV-C+US uygulaması fide boyunu \%16.99 oranında, gövde çapını \%24.56 oranında, fide yaş ağırlığını \%34.04 oranında ve fide kuru ağılığını \%37.93 oranında artırmıştır. Beith Alpha hıyar çeşidinde klorofil değeri 37.78-42.80 spad arasında değişmiştir. En yüksek klorofil içeriği UV-C+US uygulamasında, en düşük 
kllorofil içeriği ise istatistiksel olarak aynı grupta yer alan US ve UV-C uygulamalarında saptanmıştır. Beith Alpha hıyar çeşidinde UV-C, US ve UV-C+US uygulamalarının kök uzunluğu ve yaprak sayısı hariç incelenen fide büyüme parametrelerini kontrole göre pozitif yönde etkilediği belirlenmiştir (Şekil 4).
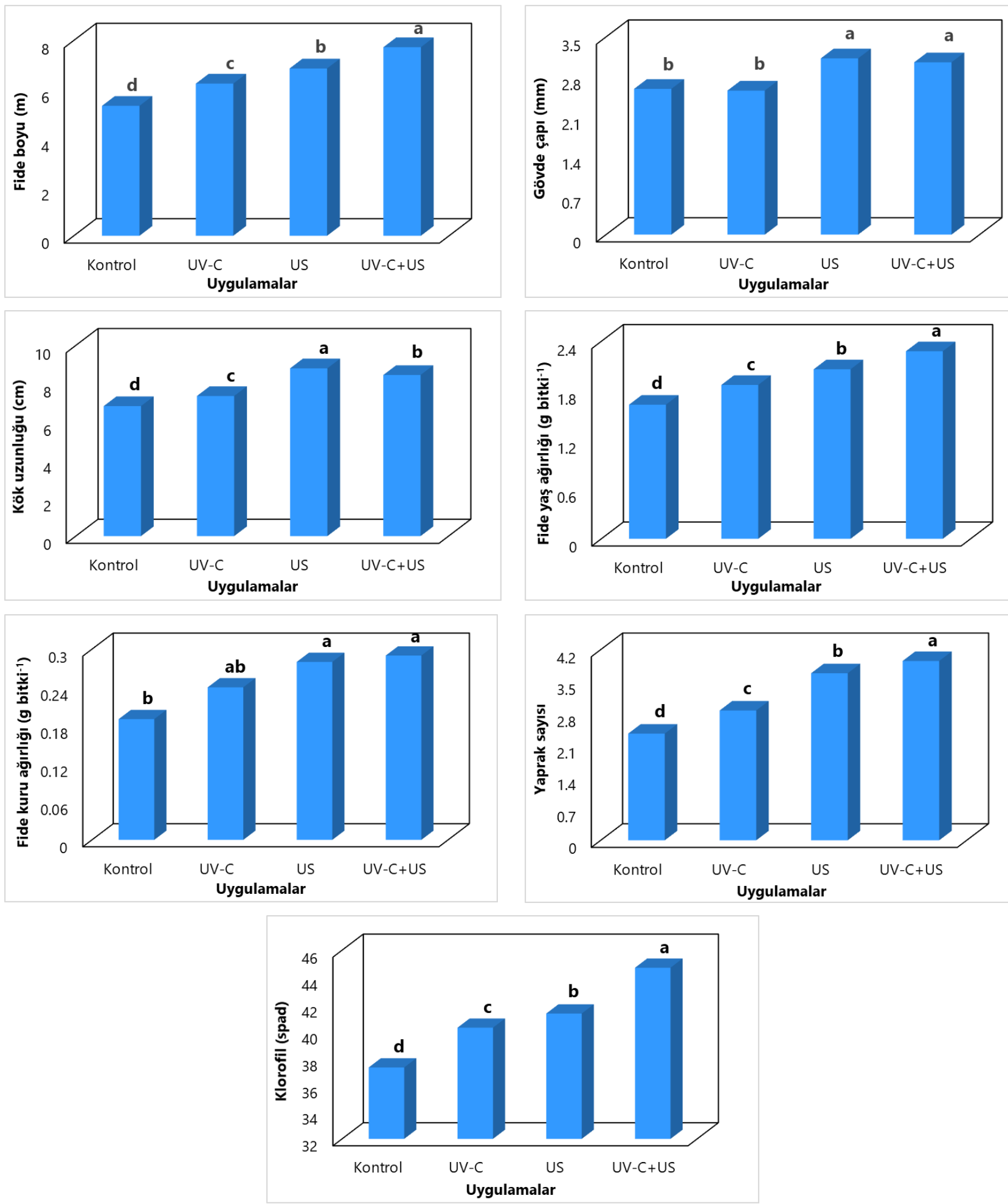

Şekil 3. Prima hıyar çeşidinde farklı uygulamaların fide büyüme parametreleri üzerine etkileri.

Figure 3. Effects of different applications on seedling growth parameters in Prima cucumber variety. 

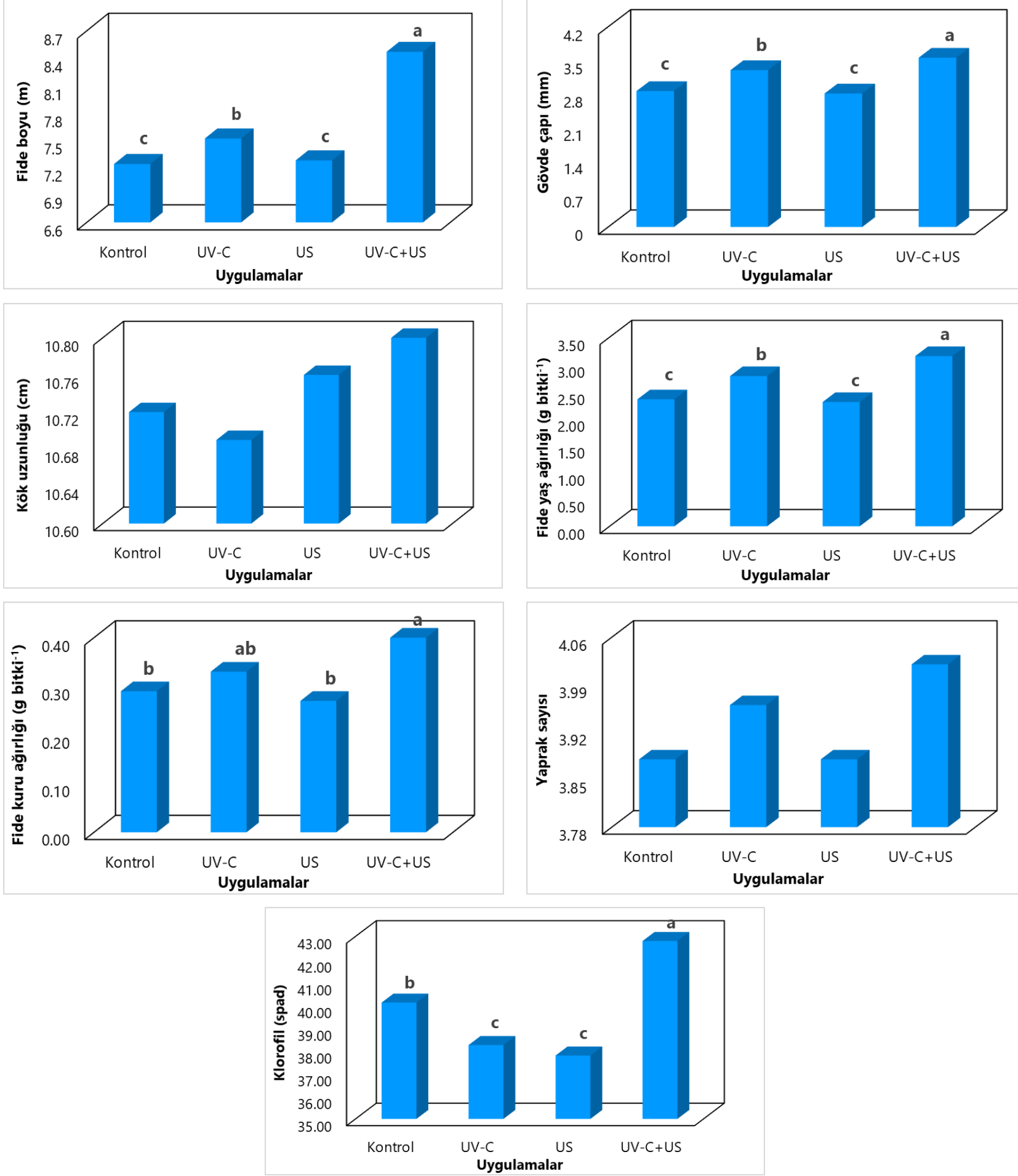

Şekil 4. Beith Alpha hıyar çeşidinde farklı uygulamaların fide büyüme parametreleri üzerine etkileri.

Figure 4. Effects of different applications on seedling growth parameters in Beith Alpha cucumber variety.

Bu çalışmada elde edilen sonuçlar, önceki çalışmalar ile uyumlu bulunmuştur. UV-C uygulaması yapılan maş fasulyesi tohumlarında çimlenme oranı, fidelerde yaprak alanı, kök, sürgün uzunluğu, kök ve sürgün kuru ağırlığının kontrole göre önemli oranda arttığı belirlenmiştir (Hamid ve Jawaid, 2011). Taze fasulye tohumlarına uygulanan UV-C ile fideler tuzluluk stresine tolerans kazanmış, sürgün ve kök yaş ağırlığında kontrole göre sırasıyla \%83 ve \%94 oranında artış sağlanmıştır (Fotouh ve ark., 2014). Ouhibi ve ark. (2014) marul tohumlarına UV-C uygulandıktan sonra tuz stresinde yetiştirilen bitkilerde UV-C uygulamasının tuzluluk stresini azaltıcı etkisinin olduğunu; çimlenme oranı, kök uzunluğu, yaprak sayısı, yaprak alanı, kök ve yaprak kuru ağırlı̆ı değerlerini artırdığını bildirmişlerdir. Barbunya fasulyesi, beyaz baş lahana, kırmızı baş lahana ve kırmızı pancar tohumlarına ekim öncesi UV uygulaması kontrole göre bitki boyu, bitki yaş ve kuru ağırlığı ile klorofil içeriğini önemli oranda artırmıştır (Kacharava ve ark., 2009). Benzer şekilde, farklı sebze türlerinde tohum ve fidelere UV uygulamasının çimlenme ve bitki gelişimini pozitif yönde etkilediği ifade edilmiştir (Li ve Kubota, 2009; Siddiqui 
ve ark., 2011; El-Shora ve ark., 2015; Kang ve ark., 2018; Mariz-Ponte ve ark., 2018; Sarı, 2019). UV radyasyonunun çimlenme ve fide gelişimi üzerindeki olumlu etkilerinin 400 nm'den düşük dalga boyuna sahip UV ışınlarının görünür ışık fotonlarından daha yüksek enerjiye sahip olmaları ve böylece fotonların hücre yüzeyinde daha fazla etki yaratmasından kaynaklandığı belirtilmektedir (Kovacs ve Keresztes, 2002). Jayakumar ve ark. (2003) UV radyasyonunun indol asetik asit (IAA) üretimini teşvik ederek bitki gelişimini olumlu yönde etkilediğini belirtmiştir. Diğer taraftan, Kara (2013) fasulyede UV-C uygulamasıyla fide boyu, yaprak büyüklüğü, yaprak sayısı ve toplam klorofil içeriğinin kontrole göre önemli oranda azaldığını belirlemiştir. Araştırıcı ayrıca fasulyede UV-C'nin bitki büyümesini ve fotosentezi olumsuz etkilediğini bildirmiştir. Yinan ve ark. (2005) hıyar fidelerinde büyüme ve gelişmenin UV uygulaması ile önemli ölçüde azaldığını ifade etmişlerdir. Aynı şekilde, farklı çalışmalarda UV uygulamasının bitki gelişimine olumsuz etkileri olduğu bildirilmiştir (Noble, 2002; Mahdavian ve ark., 2008; Liu ve ark., 2013; Choudhary ve Agraval, 2014; Zhang ve ark., 2014). Fiziksel uygulamaların bitkilere etkisi bitki türü, çeşidi, bitkinin gelişme safhası, uygulama şekli, uygulama dozu, uygulama süresi gibi çeşitli faktörlere bağlı olarak değişmektedir (De Micco ve ark., 2014).

Bu çalışmanın sonuçlarına benzer olarak biberde kısa süreli ultrason uygulamasının tohum çimlenmesi ve fide gelişimine olumlu etkilerinin olduğu bildirilmiştir (Stratu ve ark., 2010). Ultrason uygulaması maş fasulyesinde toplam klorofil içeriğini kontrole göre önemli oranda artırmıştır (Babu ve Swamy, 2012). Domates ve dereotu tohumlarına ultrason uygulamasının kontrole göre çimlenme parametrelerini (çimlenme oranı, kök ve sürgün uzunluğu) artırdığı ifade edilmiştir (Ramteke ve ark., 2015). Goussous ve ark. (2010) bezelye ve karpuzda ultrason uygulaması ile kontrole göre çimlenme oranı ve hızının arttığını, biberde ise azaldığını bildirmişlerdir. Soya fasulyesi tohumlarına ultrason uygulaması çimlenme oranı, sürgün uzunluğu ve sürgün yaş ağırlığını kontrole göre önemli oranda artırmıştır. Bununla birlikte kök uzunluğu ve kök yaş ağırlığı kontrolden daha düşük bulunmuştur (Yang ve ark., 2015). Tohumlara ultrason uygulamalarının havuç (Aladjadjiyan, 2002), bezelye (Ciu ve Sung, 2014), maş fasulyesi (Miano ve ark., 2016) ve brokkoli (Kim ve ark., 2006) gibi sebze türlerinde çimlenmeyi teşvik ettiği bildirilmiştir. Chen ve ark. (2013) ultrason uygulaması ile çimlenme oranının artmasını, ultrason titreşimlerinin enzimlerin hücre duvarından salınmasını ve biyokimyasal metabolizmayı iyileştirmesinden kaynaklanabileceğini bildirmişlerdir. Aladjadjiyan (2007) ultrason uygulamasının etkisiyle bitki gelişiminin teşvik edilmesinin, elektronfoton etkileşimleri nedeniyle moleküler enerjinin artmasıyla açılanabileceğini ifade etmiştir.

\section{SONUÇ}

Son zamanlarda bitki büyümesini teşvik etmek için alternatif fiziksel yöntemlerinin kullanımına olan ilgi artmıştır. Fiziksel yöntemler arasında yer alan ultraviyole ışınlar ve ultrason, çimlenme, çıkış, fide ve bitki gelişimi üzerinde faydalı etkiler sağlayabilmekte olup, ekolojik olarak güvenli ve çevre dostu yöntemler olarak ön plana çıkmaktadır. Bu çalışmada, Falcon ve H-2274 domates çeşitleri ile Prima ve Beith Alpha hıyar çeşitlerinde UV-C ve ultrason uygulamalarının fide gelişimi üzerine etkileri incelenmiştir. Araştırmadan elde edilen bulgulara göre UVC, US ve UV-C+US uygulamalarının domateste Falcon çeşidinde klorofil miktarı hariç incelenen tüm fide büyüme parametrelerini, H-2274 çeşidinde ise kök uzunluğu ve yaprak sayısı hariç incelenen tüm fide büyüme parametrelerini kontrole göre önemli oranda artırdığı tespit edilmiştir. Aynı şekilde, UV-C, US ve UV-C+US uygulamaları hıyarda Prima çeşidinde incelenen tüm fide büyüme parametrelerini, Beith Alpha çeşidinde ise kök uzunluğu ve yaprak sayısı hariç incelenen tüm fide büyüme parametrelerini kontrole göre önemli oranda artırmıştır. Genel olarak, UV-C ve US uygulamaları ile her ikisinin kombinasyonunun fide büyüme parametrelerine pozitif yönde etkilerinin olduğu belirlenmiştir. Uygulamalar değerlendirildiğinde, özellikle UV-C+US uygulamasının araştırmada ele alınan 4 çeşitte de fide gelişimi üzerinde daha etkili olduğu saptanmıştır. Kontrol uygulaması ile karşılaştırıldığında, UV-C+US uygulaması Falcon domates çeşidinde fide boyunu \%26.74 ve fide yaş ağırlığını \%24.82 oranında; $\mathrm{H}-2274$ domates çeşidinde fide boyunu \%25.99, fide yaş ağırlığını \%30.50 ve fide kuru ağırlığını \%47.62 oranında artırmıştır. Aynı şekilde, UV-C+US uygulaması kontrole göre Prima hıyar çeşidinde fide boyunu \%45.11, fide yaş ağırlığını \%39.88, fide kuru ağılığını \%52.63 ve yaprak sayısını \%68.09 oranında; Beith Alpha hıyar çeşidinde fide boyunu \%16.99, fide yaş ağırlığını \%34.04 ve fide kuru ağırlığını \%37.93 oranında artırmıştır. UV-C, US ve UV-C+US uygulamalarının domates ve hıyarda fide gelişimini artırmada alternatif bir uygulama yöntemi olarak başarılı bir şekilde kullanılabileceği sonucuna varılmıştır. Bununla birlikte, bu uygulamaların etkinliklerinin arazi koşullarında ve farklı sebze türlerinde daha detaylı olarak incelenmesinin gerekli olduğu düşünülmektedir. 


\section{ÇIKAR ÇATIŞMASI}

Yazar olarak makalenin planlanması, yürütülmesi ve yazılması konusunda herhangi bir çıkar çatışması olmadığını beyan ederim.

\section{YAZAR KATKISI}

Yazar olarak makalenin planlanması, yürütülmesi ve yazımı tarafımca yapılmıştır.

\section{TEŞEKKÜR}

Bu çalışmanın yapılmasında yardımcı olan Doç. Dr. İhsan CANAN'a teşekkür ederim.

\section{KAYNAKLAR}

Aladjadjiyan, A. (2002). Increasing carrot seeds (Daucus carota L.), cv. Nantes, viability through ultrasound treatment. Bulgarian Journal of Agricultural Science, 8, 469-472.

Aladjadjiyan, A. (2007). The use of physical methods for plant growing stimulation in Bulgaria. Journal of Central European Agriculture, 3, 369-380.

Aladjadjiyan, A. (2012). Physical factors for plant growth stimulation improve food quality. In: Aladjadjiyan A (ed) Food Production: Approaches, Challenges and Tasks. IntechOpen, 145-168.

Amini, F., \& Ehsanpour, A. A. (2005). Soluble proteins, proline, carbohydrates and $\mathrm{Na}^{+} / \mathrm{K}^{+}$changes in two tomato (Lycopersicon esculentum Mill.) cultivars under in vitro salt stress. American Journal of Biochemistry and Biotechnology, 1(4), 212-216.

Awad, T., Moharram, H., Shaltout, O., Asker, D., \& Youssef, M. (2012). Applications of ultrasound in analysis, processing and quality control of food: A review. Food Research International, 48(2), 410-427.

Babu, B. S., \& Swamy, P. M. (2012). Effect of ultra sound on physiological parameters in cultivars of Vigna radiata. Asian Journal of Plant Science and Research, 2(2), 163-172.

Chen, Y. P., Liu, Q., Yue, X. Z., Meng, Z. W., \& Liang, J. (2013). Ultrasonic vibration seeds showed improved resistance to cadmium and lead in wheat seedling. Environmental Science and Pollution Research, 20(7), 4807-4816.

Choudhary, K. K., \& Agrawal, S. B. (2014). Ultraviolet-B induced changes in morphological, physiological and biochemical parameters of two cultivars of pea (Pisum sativum L.). Ecotoxicology and Environmental Safety, 100, 178-187.

Ciu, K. Y., \& Sung, J. M. (2014). Use of ultrasonication to enhance pea seed germination and microbial quality of pea sprouts. International Journal of Food Science and Technology, 49, 1699-1706.

De Micco, V., Paradiso, R., Aronne, G., De Pascale, S., Quarto, M., \& Arena, C. (2014). Leaf anatomoy and photochemical behaviour of Solanum lycopersicum L. plants from seeds irradiated with low-LET ionising radiation. The Scientific World Journal, 2014, 1-14.

Dhanya Thomas, T. T., \& Puthur, J. T. (2017). UV radiation priming: A means of amplifying the inherent potential for abiotic stress tolerance in crop plants. Environmental and Experimental Botany, 138, 57-66.

Dhiman, M. R., \& Prakash, C. (2005). Correlation and path coefficient analysis in cucumber. Haryana Journal of Horticultural Sciences, 34(1-2), 111-112.

El-Shora, H. M., El-Farrash, A. H., Kamal, H., \& Abdelrazek, A. (2015). Enhancement of antioxidant defense system by UV radiation in fenugreek as medical plant. International Journal of Science and Research, 3, 529-535.

FAOSTAT. (2018). Statistical databases. Food and Agriculture Organization of the United Nations. http://faostat.fao.org. Erişim tarihi: 15 Eylül 2020.

Fotouh, A. M. M., Moawad, F. G., El-Naggar, H. A., El-Din, M. T., \& Eldeen, H. S. (2014). Influence of seed treatment with UV-C on saline stress tolerance in green beans (Phaseolus vulgaris L.). Journal of Biological Chemistry and Environmental Sciences, 9(2), 391-414.

Frederick, J. E. (1993). Ultraviolet sunlight reaching the earth's surface: A review of recent research. Photochemistry and Photobiology, 57(1), 175-178.

Goussous, S. J., Samarah, N. H., Alqudah, A. M., \& Othman, M. O. (2010). Enhancing seed germination of four crops species using an ultrasonic technique. Experimental Agriculture 46, 231-242. 
Hamid, N., \& Jawaid, F. (2011). Influence of seed pre-treatment by UV-A and UV-C radiation on germination and growth of Mung beans. Pakistan Journal of Chemistry, 1, 164-167.

Hollosy, F. (2002). Effects of ultraviolet radiation on plant cells. Micron, 33(2), 179-197.

Jayakumar, M., Amudha, P., \& Kulandaivelu, G. (2003). Changes in growth and yield of Phaseolus mungo L. induced by UV-A and UV-B enhanced radiation. Journal of Plant Biology, 46(1), 59-61.

Kacharava, N., Chanishvili, S., Badridze, G., Chkhubianishvili, E., \& Janukashvili, N. (2009). Effect of seed irradiation on the content of antioxidants in leaves of kidney bean, cabbage and beet cultivars. Australian Journal of Crop Science, 3(3), 137145.

Kang, S., Zhang, Y., Zhang, Y., Zou, J., Yang, Q., \& Li, T. (2018). Ultraviolet-A radiation stimulates growth of indoor cultivated tomato (Solanum lycopersicum) seedlings. HortScience, 53(10), 1429-1433.

Kara, Y. (2013). Morphological and physiological effects of UV-C radiation on bean plant (Phaseolus vulgaris). Bioscience Research, 10(1), 29-32.

Katerova, Z. I., \& Todorova, D. (2009). Endogenous polyamines lessen membrane damages in pea plants provoked by enhanced ultraviolet-C radiation. Plant Growth Regulation, 57, 145-152.

Kim, H. J., Feng, H., Kushad, M. M., \& Fan, X. (2006). Effects of ultrasound, irradiation, and acidic electrolyzed water on germination of alfalfa and broccoli seeds and Escherichia coli 0157: H7. Journal of Food Science, 71(6), 168-173.

Koutchma, T. (2009). Advances in ultraviolet light technology for non-thermal processing of liquid foods. Food and Bioprocess Technology, 2(2), 138-155.

Kovacs, E., \& Keresztes, A. (2002). Effect of gamma and UV-B/C radiation on plant cells. Micron, 33(2), $199-210$.

Li, Q., \& Kubota, C. (2009). Effects of supplemental light quality on growth and phytochemicals of baby leaf lettuce. Environmental and Experimental Botany, 67(1), 59-64.

Liu, B., Liu, X. B., Li, Y. S., \& Herbert, S. J. (2013). Effects of enhanced UV-B radiation on seed growth characteristics and yield components in soybean. Field Crops Research, 154, 158-163.

Mahdavian, K., Ghorbanli, M., \& Kalantari, K. M. (2008). The effects of ultraviolet radiation on the contents of chlorophyll, flavonoid, anthocyanin and proline in Capsicum annuum L. Turkish Journal of Botany, 32(1), 25-33.

Mariz-Ponte, N., Mendes, R. J., Sario, S., Melo, P., \& Santos, C. (2018). Moderate UV-A supplementation benefits tomato seed and seedling invigoration: A contribution to the use of UV in seed technology. Scientia Horticulturae, 235, 357-366.

Miano, C. A., Costa Pereira, J., Castanha, N., Matta Junior, M. D., \& Augusto, E. D. (2016). Enhancing mung bean hydration using the ultrasound technology: Description of mechanisms and impact on its germination and main components. Scientific Reports, 6, 1-14.

Noble, R. E. (2002). Effects of UV-irradiation on seed germination. Science of the Total Environment, 299(1-3), 173-176.

Ouhibi, C., Attia, H., Rebah, F., Msilini, N., Chebbi, M., Aarrouf, J., Urban, L., \& Lachaal, M. (2014). Salt stress mitigation by seed priming with UV-C in lettuce plants: Growth, antioxidant activity and phenolic compounds. Plant Physiology and Biochemistry, 83, 126-133.

Ramteke, A. A., Meshram, U. P., \& Yaul, A. R. (2015). Effect of ultrasonic waves on seed germination of Lycopersicon esculentum and Anethum graveolens. International Journal of Chemical and Physical Sciences, 4, 333-336.

Rifna, E. J., Ramanan, K. R., \& Mahendran, R. (2019). Emerging technology applications for improving seed germination. Trends in Food Science \& Technology, 86, 95-108.

Sarı, M. E. (2019). Ultraviyole (UV), manyetik alan (MA) ve hidropriming (HP) uygulamalarının biber, lahana, marul ve soğan tohumlarında kalitenin iyileştirilmesinde kullanımı. Doktora Tezi, Ankara Üniversitesi, Fen Bilimleri Enstitüsü, Ankara.

Sharma, B. D., \& Hore, D. K. (1996). Indian cucumber germplasm and challenges ahead. Genetic Resources and Crop Evolution, $43,7-12$.

Shetta, D. N., \& Areaf, M. I. (2009). Impact of ultraviolet-C radiation on seed germination and chlorophyll concentration of some woody trees grown in Saudi Arabia. Journal of Agriculture and Environmental Sciences, 8, 1-21.

Siddiqui, A., Dawar, S., Zaki, M. J., \& Hamid, N. (2011). Role of ultra violet (UV-C) radiation in the control of root infecting fungi on groundnut and mung bean. Pakistan Journal of Botany, 43(4), 2221-2224.

Stratu, A., Peptanariu, M., Sarghi, V., \& Costica, N. (2010). Aspects regarding the behaviour of the Capsicum annuum L. species to the ultrasound treatment. Lucrari Stiintifice, 53(1), 69-72.

TÜiK. (2020). Bitkisel üretim istatistikleri. http://www.tuik.gov.tr._Erişim tarihi: 10 Eylül 2020. 
Tüzel, Y., Gül, A., Öztekin, G. B., Engindeniz, S., Boyacı, F., Duyar, H., Cebeci, \& E., Durdu, T. (2020). Türkiye'de örtüaltı yetiştiriciliği ve yeni gelişmeler. Türkiye Ziraat Mühendisliği IX. Teknik Kongresi, Ankara.

Vasilevski, G. (2003). Perspectives of the application of biophysical methods in sustainable agriculture. Bulgarian Journal of Plant Physiology, 29,179-186.

Vural, H., Eşiyok, D., \& Duman, İ. (2000). Kültür Sebzeleri (Sebze Yetiştirme). Ege Üniversitesi Basımevi, İzmir.

Wang, Q., Chen, G., Yersaiyiti, H., Liu, Y., Cui, J., Wu, C., Zhang, Y., \& He, X. (2012). Modeling analysis on germination and seedling growth using ultrasound seed pretreatment in switchgrass. Plos One, 7(10), 1-10.

Yaldagard, M., Mortazavi, S. A., \& Tabatabaie, F. (2008). Application of ultrasonic waves as a priming technique for accelerating and enhancing the germination of barley seed: Optimization of method by the Taguchi approach. Journal of Institute of Brewing, 114(1), 14-21.

Yang, H. B., Ding, W. M., Chen, K. J., \& Ding, Y. Q. (2004). Application of ultrasonic technique in agriculture-actuality and prospect. Journal of Agricultural Mechanization Research, 1, 365-370.

Yang, H., Gao, J., Yang, A., \& Chen, H. (2015). The ultrasound-treated soybean seeds improve edibility and nutritional quality of soybean sprouts. Food Research International, 77, 704-710.

Yinan, Y., Yuan, L., Yongqing, Y., \& Chunyang, L. (2005). Effect of seed pretreatment by magnetic field on the sensitivity of cucumber (Cucumis sativus) seedlings to ultraviolet-B radiation. Environmental and Experimental Botany, 54, $286-294$.

Zhang, L., Allen, L. H., Vaughan, M. M., Hauser, B. A., \& Boote, K. J. (2014). Solar ultraviolet radiation exclusion increases soybean internode lengths and plant height. Agricultural and Forest Meteorology, 184, 170-178. 